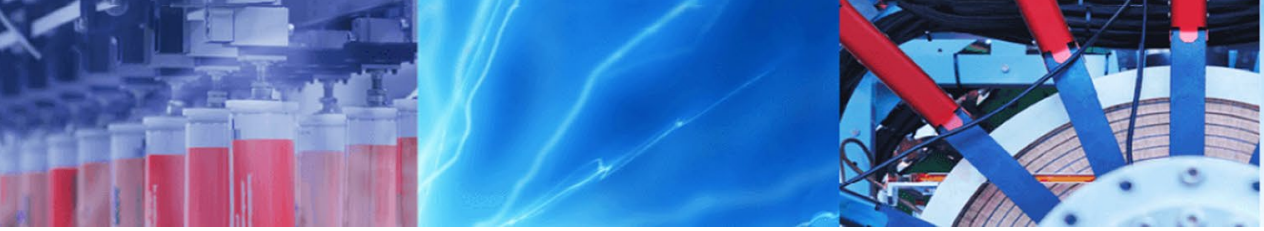

Research Article

\title{
Combined effects of rice husk ash and nylon fiber on engineering properties of cement mortar
}

\author{
Lalani Fernando ${ }^{1} \cdot$ Karunananda Pemasiri $^{1,2} \cdot$ Buddhika Dassanayake ${ }^{1,2}$ (D)
}

Received: 18 December 2019 / Accepted: 5 February 2020 / Published online: 10 February 2020

(c) Springer Nature Switzerland AG 2020

\begin{abstract}
Utilization of waste materials is of utmost importance in creating a sustainable future. Industrial waste as well as recycled materials are used as supplementary cementitious materials in order to preserve the environment as well as to enhance the properties of the construction material. In the reporting work, rice husk ash (RHA) and nylon fibers were added to cement mortar (a mixture of cement, sand and water) to investigate their individual, as well as combined effect on flexural and compressive strengths, sorptivity, and abrasion resistance of cement mortar. Test results obtained in this study indicate that RHA can be blended up to $10 \%$ by weight of cement to obtain higher flexural and compressive strengths as the addition of RHA improves the strength of the cement paste by enhancing the production of calcium-silicatehydrate. Nylon fiber reinforcement with 0.5 vol\% showed efficient increment in flexural and compressive strengths of the mortar as a result of fibers holding the elements of the composite together. Replacement of cement with $10 \mathrm{wt} \% \mathrm{RHA}$ effectively reduced the sorptivity of mortar as the addition of RHA results in the formation of a dense calcium-silicatehydrate structure reducing the porosity and blocking the capillaries inside the paste. Addition of 0.5 vol\% nylon fiber to the cement replaced with $10 \mathrm{wt} \%$ RHA showed an increase in abrasion resistance of the mortar as nylon fibers can retain during longer time period of stress due to their high elasticity. Overall results indicated that the combined addition of rice husk ash and nylon fibers can increase the performance of cement mortar effectively by increasing its mechanical as well as durability properties.
\end{abstract}

Keywords Cement mortar · Nylon fiber · Pozzolanic material · Rice husk ash · Supplementary cementitious material

\section{Introduction}

Concrete/mortar is the most widely used construction material because of its strength, durability, versatility and availability of raw materials. Engineers and scientists have been investigating on low cost methods for many years to improve the properties of concrete/mortar while maintaining sustainability. Addition of supplementary cementitious materials (SCMs) plays a significant role in this matter. Various SCMs such as fly ash, rice husk ash, silica fume and ground granulated blast furnace slag are used as a partial cement replacement [1, 2]. Use of SCMs conserves energy and has environmental benefits because of the reduction in carbon dioxide emission as a result of reduction in manufacture of Portland cement. At the same time, it is a cost-effective solution as most of the SCMs are cheaper when compared to cement [2].

Utilization of waste materials is an essential step in creating a sustainable future. Rice husk, which is the outer covering of rice grain, is one of the most widely available agricultural wastes in many rice producing countries. In majority of these countries, much of the husk produced is either burnt or dumped as waste after processing of rice. By subjecting rice husk to a simple combustion process,

Buddhika Dassanayake, buddhikad@pdn.ac.lk| 'Department of Physics, Faculty of Science, University of Peradeniya, Peradeniya 20400, Sri Lanka. ${ }^{2}$ Postgraduate Institute of Science, University of Peradeniya, Peradeniya 20400, Sri Lanka. 
rice husk ash can be obtained with more than $90 \%$ noncrystalline silica; which acts as a highly pozzolanic material [3]. Thus, rice husk ash can be used as a SCM to improve the performance of concreter/mortar.

Plain concrete/mortar is characterized as a brittle material with low tensile strength and low tensile strain capacities $[4,5]$. They are often crack ridden and fracture forming during plastic and hardened states. Therefore, reinforcement is needed to be done before using them as construction materials. From ancient times continuous reinforcing bars are used as reinforcing materials. They could be placed in the structure at appropriate locations to withstand the imposed tensile and shear stresses. Usage of relatively short, discrete and discontinuous fibers as reinforcing materials has been steadily increasing in recent years. Fiber reinforcement is effective when compared to reinforcing bars, as they can be randomly distributed throughout the cementitious matrix. They tend to be more closely spaced than conventional reinforcing bars, and thus they effectively control cracking $[4,5]$. A wide range of fibers with different mechanical, physical and chemical properties are used as reinforcing materials. Conventional fibers such as steel and glass; new fibers such as carbon and Kevlar; and low modulus fibers, either man-made (polypropylene, nylon) or natural (cellulose, sisal, jute) stand out among them $[4,5]$.

The reporting work was carried out to improve the performance of conventional cement mortar by incorporating rice husk ash as a SCM, and nylon fiber as a reinforcing material.

\section{Materials and methods}

\subsection{Materials used}

Ordinary Portland cement (OPC) conforming to Sri Lanka Standard Specification (SLS) 107:2008 was used. Graded river sand passing through $2 \mathrm{~mm}$ sieve was used as the fine aggregate. Commercially available nylon fiber was obtained and manually cut into $2 \mathrm{~cm}$ pieces.

Rice husk was washed well with water and burnt in fire to obtain black color rice husk ash. Then this ash was burnt in the furnace at a temperature of $700^{\circ} \mathrm{C}$ for $6 \mathrm{~h}$ to obtain white color RHA [3]. For the sample preparation, RHA were ball milled and sieved using $32 \mu \mathrm{m}$ sieve.

\subsection{Sample preparation}

Plain mortar was prepared by mixing cement: water: sand at a ratio of 1:0.5:3, according ASTM C305 standard mortar mixing procedure [6]. Nylon fiber was

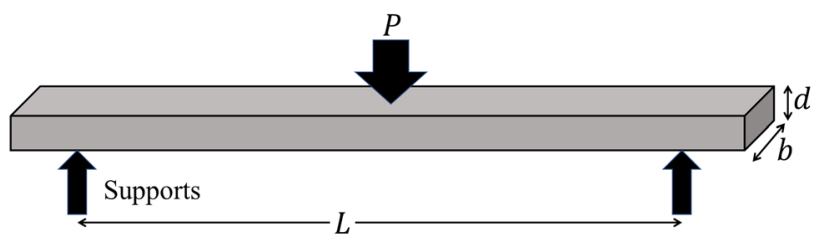

Fig. 1 Schematic diagram of the three-point loading test

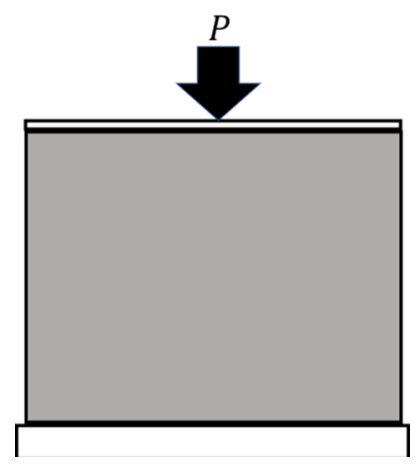

Fig. 2 Schematic diagram of the compressive strength test

mixed with plain mortar by hand for about $15 \mathrm{~min}$. Nylon fiber percentages were varied from 0.25 to $3.0 \%$ by volume of mortar. The cement was replaced with RHA from 5 to $25 \%$ by weight of cement to study its effect on properties of mortar.

\subsection{Characterization}

Flexural strength, also known as the modulus of rupture is the ability of a material to resist deformation under a load. According to standard method specified in ASTM C348, flexural strength of mortar cubes is obtained by three-point loading test [7]. In this method, a load is applied to the sample as shown in Fig. 1 and flexural strength is calculated using Eq. 2.1.

$S_{f}=\frac{3 P L}{2 b d^{2}}$

where $S_{f}$ is the flexural strength, $P$ is the total maximum load, $L$ is the support span, $b$ is the width and $d$ is the thickness of the block [8].

According ASTM C348, $4 \times 4 \times 16 \mathrm{~cm}^{3}$ blocks were moisture cured for 7 days and tested using the universal testing machine [7]. A load was applied until the sample was broken, and the flexural strength was calculated using Eq. $2.1[9,10]$.

Compressive strength is the maximum compressive stress that a given solid material can sustain without 
fracture, under a gradually applied load [8]. Application of force was done as shown in Fig. 2. According to standard method specified in ASTM C349, compressive strength of mortar cubes was determined by Eq. 2.2 [11].

$S_{c}=\frac{P}{A}$

where $S_{c}$ is the compressive strength, $P$ is the total maximum load and $A$ is the area perpendicular to the load.

According ASTM C349, portions of prisms broken in flexure were tested using the Universal testing machine [11]. Sample was compressed until the sample was broken, and the compressive strength was calculated using Eq. 2.2.

Coefficient of water absorption was estimated by measuring the rate of uptake of water by dry mortar in a period of $1 \mathrm{~h}$ in order to determine the sorptivity. Mortar samples of $5 \times 5 \times 5 \mathrm{~cm}^{3}$ were preconditioned by keeping in a moisture tight container for 7 days and then drying in an oven at $105^{\circ} \mathrm{C}$ for $24 \mathrm{~h}$ until a constant weight was reached. Then the samples were allowed to cool in a sealed container for about $2 \mathrm{~h}$ and they were kept partially immersed to a depth of $3 \mathrm{~mm}$ on the casted surface. The quantity of water absorbed during the first 60 min was then determined and the Coefficient of water absorption values of mortar samples were calculated using Eq. $(2.3)[12,13]$.

$K_{a}=\left(\frac{Q}{A}\right)^{2} \times\left(\frac{1}{t}\right)$

where $K_{a}$ is the coefficient of water absorption, $Q$ is the quantity of water absorbed in time $t, A$ is the surface area through which water penetrates and $t$ is the time period at which block is in contact with water.

Rate of water absorption was determined according to the standard method specified in ASTM C1403 [14].

Abrasion resistance was investigated using a homemade apparatus which was prepared by attaching a grinding disc to a drilling machine. Prior to testing, the $5 \times 5 \times 5 \mathrm{~cm}^{3}$ mortar blocks were moisture cured for 7 days and then kept in a moisture tight container for 3 days. Then the casted surfaces of samples were ground for about 10 and $20 \mathrm{~min}$ and the mass reduction were determined according to the Eq. (2.4) after each time period.

$\left(\begin{array}{l}\text { Mass } \\ \text { reduction }\end{array}\right)=\left(\begin{array}{l}\text { Initial mass } \\ \text { before grinding }\end{array}\right)-\left(\begin{array}{l}\text { Final mass } \\ \text { after grinding }\end{array}\right)$

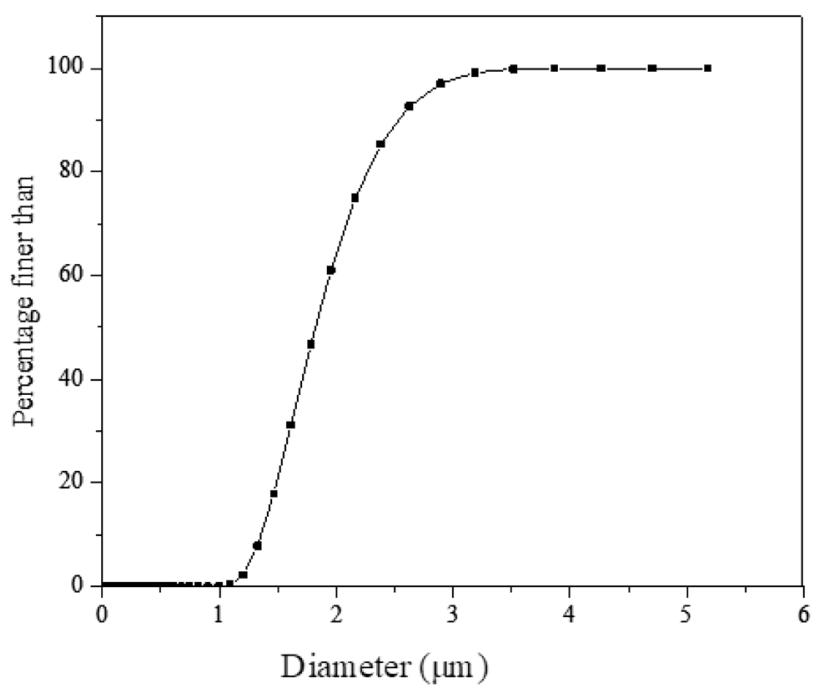

Fig. 3 Particle size distribution curve of OPC

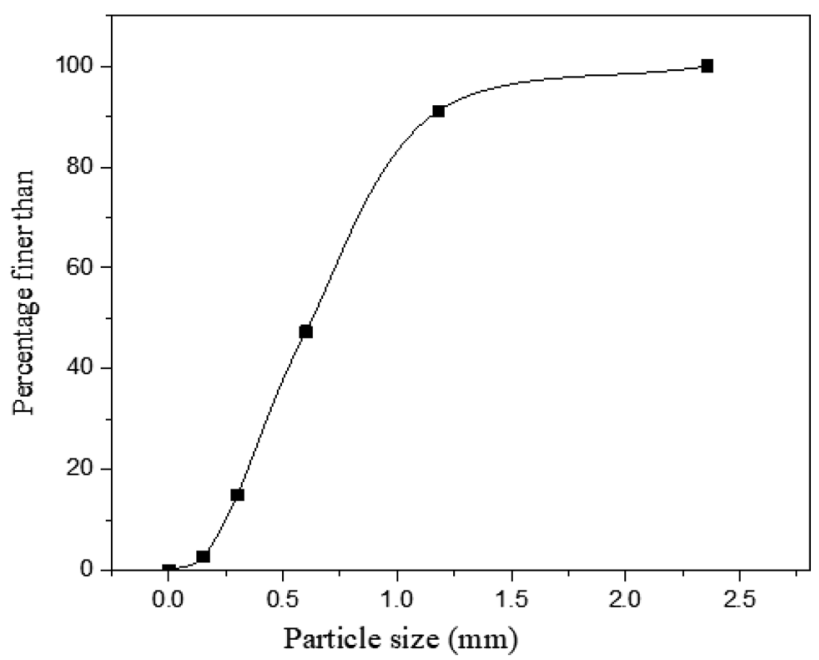

Fig. 4 Particle size distribution curve of sand

\section{Results and discussion}

\subsection{Physical analysis of Materials}

\subsubsection{Ordinary Portland cement (OPC)}

Particle size distribution curve of OPC obtained using the Cilas Nano DS Dual Light Scattering Particle Size Analyzer is shown in Fig. 3. According to the graph, OPC particle size is about $1-3 \mu \mathrm{m}$. 


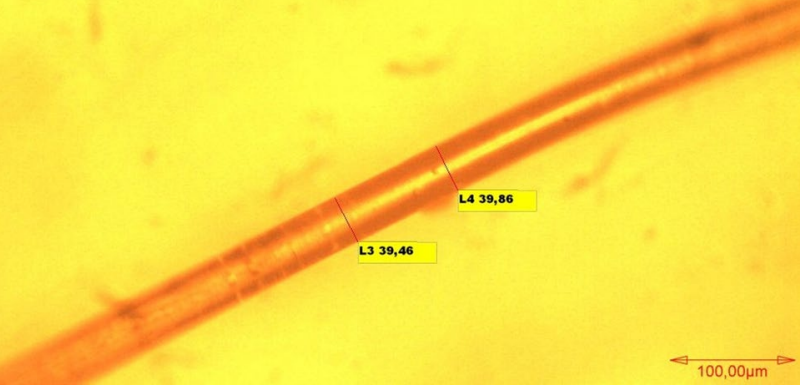

Fig. 5 Polarization microscope image of nylon fiber

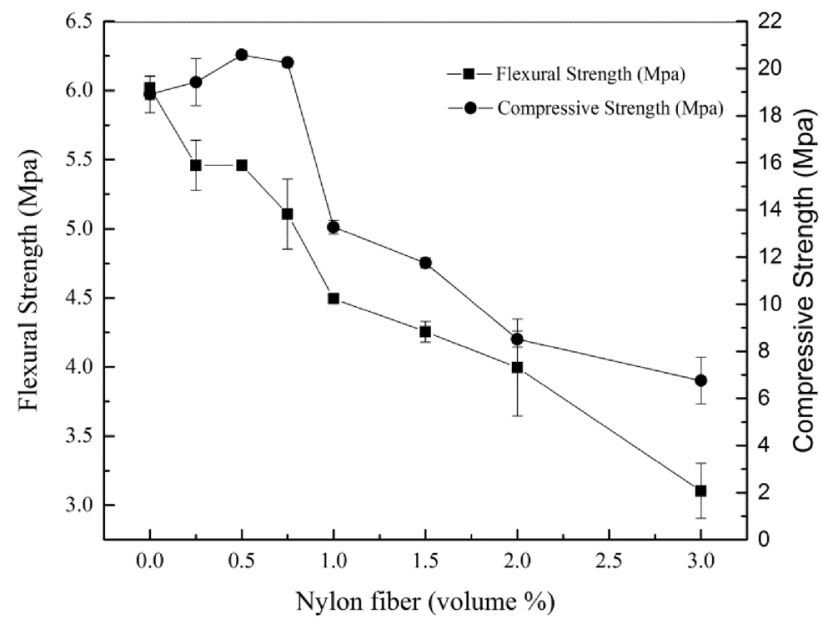

Fig. 6 Variation of flexural and compressive strength with varying nylon fiber volume percentage

Particle size distribution curve of sand obtained using sieve analysis is shown in Fig. 4. Sand particle sizes were ranging from 0 to $2 \mathrm{~mm}$.

\subsubsection{Nylon fiber}

Figure 5 shows a Polarization microscope image indicating the average diameter of nylon fiber. The diameter of nylon fiber is about $40 \mu \mathrm{m}$.

\subsection{Strength of nylon fiber reinforced cement mortar}

\subsubsection{Flexural strength}

Results obtained for the flexural strength of fiber reinforced mortar samples with changing fiber percentage are shown in Fig. 6. As fiber content was increased, the flexural strength of mortar decreased significantly. This reduction can be due to fibers not being well bound with mortar after 7 days. As a result, fibers can de-bond from mortar easily at lower loads.

Although the failure occurred at higher load values, unreinforced mortar specimen exhibited brittle behavior in breaking due to a sudden rupture on reaching the peak load. On the other hand, fiber reinforced mortar specimens showed a more ductile failure mode, holding the elements of the fractured composite together, reducing the potential for catastrophic failure as well as the danger of fragments flying away at a variety of directions from the face of the composite [15].

\subsubsection{Compressive strength}

The variation of the compressive strength of mortar blocks with changing nylon fiber volume percentage is shown in Fig. 6. As the fiber percentage was increased, the compressive strength of mortar blocks increased up to 0.5 vol\% fiber and then it started to decrease. The increase in compressive strength is possible since, as the blocks are well compacted with fibers, they can resist higher loads than plain mortar under compression. After $0.5 \%$, the compressive strength of mortar samples decreased with increasing Nylon percentage. This may be due to the incomplete compaction which may have occurred as a result of reduced workability of the mixture with the increasing amount of fibers [16].

By considering both flexural and compressive strength behavior of mortar with changing fiber percentages, 0.5 vol\% fiber was selected as the optimum reinforcement level.

\subsection{Strength of RHA blended cement mortar}

\subsubsection{Flexural strength}

Figure 7 shows the variation of flexural strength of mortar with the increase in RHA perecentages. Flexural strength did not show any significant change up to $15 \%$ replacement of cement with RHA. But after 15\%, it decreased significantly. This can be due to many reasons. The addition of RHA makes the cement paste more denser by forming more $\mathrm{C}-\mathrm{S}-\mathrm{H}$ gel, thus decreasing the porosity and blocking capillaries inside the paste $[15,17]$. This may block the water transfer to the un-hydrated particles for more hydration. Reduction in amount of calcium silicate supply for the hydration process with the reduction of amount of cement may be another reason for the decrement of flexural strength of mortar. Also, due to high specific surface 


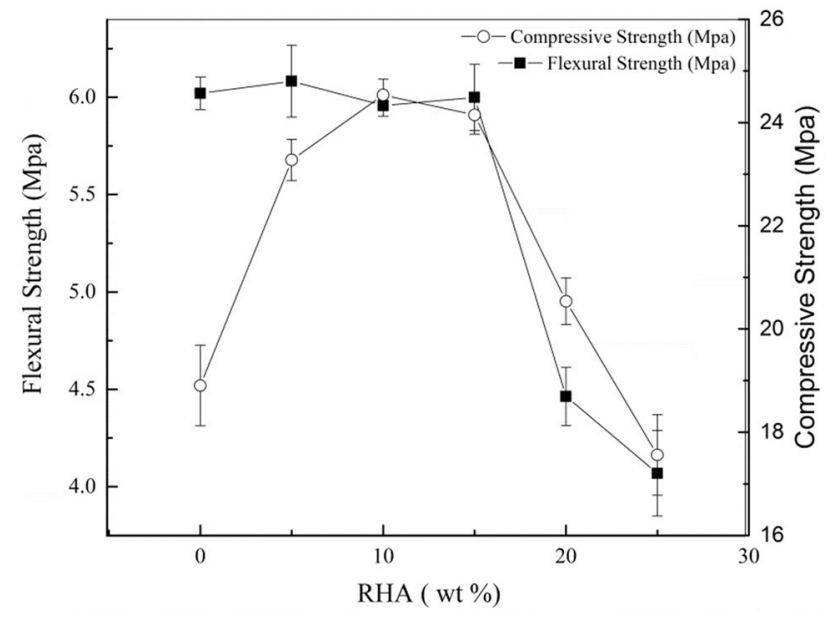

Fig. 7 Variation of flexural and compressive strength of mortar with varying RHA percentage

area of RHA, they are likely to stick together through a physical bonding rather than contributing for the hydration process. This can also reduce the strength of mortar.

\subsubsection{Compressive strength}

The inclusion of RHA as a partial replacement of cement enhanced the compressive strength of mortar blocks. Maximum strength was obtained at $10 \%$ RHA as shown in Fig. 7. After 10\% RHA, compressive strength started to decrease. However, compressive strength values were higher than that of plain mortar up to $20 \%$ of RHA. Higher compressive strength observed for RHA blended mortar could potentially be due to enhancement of the formation of $\mathrm{C}-\mathrm{S}-\mathrm{H}$ gel by finer RHA.

When water is added to cement, each of the compounds undergo hydration. Calcium in cement reacts with sand and water to produce calcium silicate, dicalcium silicate and tricalcium silicate. But only calcium silicates contribute to strength of the paste. Tricalcium silicate, which is highly reactive, is responsible for the early stage strength of mortar and dicalcium silicate, which is less reactive, contributes only to the strength at later times [18]. The hydration process of tricalcium silicate is shown by reaction 3.1.

$2\left(3 \mathrm{CaO} \cdot \mathrm{SiO}_{2}\right)+6 \mathrm{H}_{2} \mathrm{O} \rightarrow 3 \mathrm{CaO} \cdot 2 \mathrm{SiO}_{2} \cdot 3 \mathrm{H}_{2} \mathrm{O}+3 \mathrm{Ca}(\mathrm{OH})_{2}$

In the hydration process, tricalcium silicate rapidly reacts with water to release calcium ions, hydroxide ions, and a large amount of heat. As a result of the release of alkaline hydroxide $(\mathrm{OH}-)$ ions, the $\mathrm{pH}$ value of the paste quickly rises over 12 . This initial hydrolysis slows down quickly after it starts resulting in a decrease in the heat evolved. The reaction slowly continues producing calcium and hydroxide ions until the system becomes saturated. Once the saturation is reached, calcium hydroxide starts to crystallize and the formation of a dense structure called calcium silicate hydrate (also called $\mathrm{C}-\mathrm{S}-\mathrm{H}$ gel) begins.

The $\mathrm{C}-\mathrm{S}-\mathrm{H}$ crystals grow thicker making it more difficult for water molecules to reach the un-hydrated tricalcium silicate. The speed of the reaction is now controlled by the rate at which water molecules diffuse through the calcium silicate hydrate coating. This paste thickens over time causing the production of $\mathrm{C}-\mathrm{S}-\mathrm{H}$ to become slower and slower. The $\mathrm{C}-\mathrm{S}-\mathrm{H}$ gel hardens with age to form a continuous binding matrix with a large surface area and it is the main strengthening constituent in the cement paste [18].

Due to high specific area of RHA, a more homogenous and a denser paste is created with lesser porosity and lesser width of interfacial zone between the paste and the aggregate [19]. Thus, the strength is increased. After $20 \%$ replacement of cement with RHA, the water transfer to the un-hydrated particles for more hydration would have been blocked and with the reduction of amount of cement, amount of calcium silicate supply for the hydration process may be reduced. Also sticking of RHA particles together due to their high specific surface area can occurr and hence the strength can be decreased.

By considering both flexural and compressive strength test results, $10 \%$ replacement of cement by RHA was chosen as the optimum RHA replacement level.

\subsection{Strength of fiber reinforced mortar with RHA}

\subsubsection{Flexural strength}

By keeping the reinforced fiber percentage at 0.5 vol\% which was chosen as the optimum fiber percentage, RHA weight percentage was changed from 0 to $25 \%$ for further investigation of the effect of RHA on nylon fiber reinforced mortar. The variation of flexural strength of fiber reinforced mortar with the replacement of cement with RHA is shown in Fig. 8.

With the increase of replacement of cement with RHA, the flexural strength of $0.5 \%$ fiber reinforced mortar did not show a significant change up to $5 \%$. After $10 \%$ of RHA, the flexural strength was decreased. The fine RHA particles with high specific surface area can reach small pores in between the cement and fibers to produce more $\mathrm{C}-\mathrm{S}-\mathrm{H}$ gel. This resuts in reduction of the width of the interfacial transition zones between the aggregate, fibers and cement paste [4]. This may decrease the flexural strength by disturbing water transfer for the unhydrated calcium silicate products for further hydration. On the other hand due to the high specific surface area of RHA they are likely 


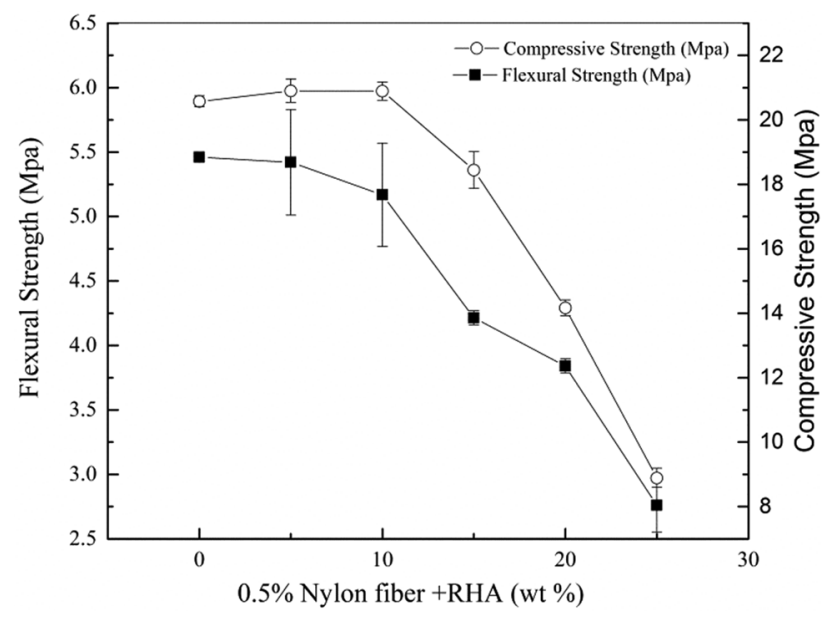

Fig. 8 Flexural strength and compressive strength versus RHA percentage for (0.5 vol\%) fiber reinforced mortar

to stick together through a physical bond rather than contributing for the hydration process. The reduction of amount of cement with increasing RHA also may be a reason for the reduction in strength of mortar.

\subsubsection{Compressive strength}

Addition of RHA to fiber reinforced mortar up to $10 \%$ of RHA increased the compressive strength slightly as seen in Fig. 8. However, it showed a significant reduction beyond replacement by $10 \%$. With the increase in replacement level of RHA strength may decrease due to blocking of water transfer to the un-hydrated particles.

\subsection{Comparison of optimized RHA and fiber incorporated mortar samples}

Considering the results obtained for flexural and compressive strengths of all these mortar samples, $0.5 \mathrm{vol} \%$ fiber and $10 \mathrm{wt} \%$ RHA were selected as the optimum incorporation levels. Then plain mortar, mortar with optimized nylon fiber $(0.5 \%)$, mortar optimized with RHA (10 wt\%) and mortar optimized with with both nylon fiber ( 0.5 vol\%) and RHA (10 wt\%) were tested for their flexural strength, compressive strength, water absorption and abrasion resistance.

\subsubsection{Flexural strength}

Flexural strength values of (a) plain mortar, (b) fiber reinforced mortar, (c) RHA blended mortar and (d) RHA blended fiber reinforced mortar, after 7 and 21 days are given in Fig. 9.

\section{SN Applied Sciences}

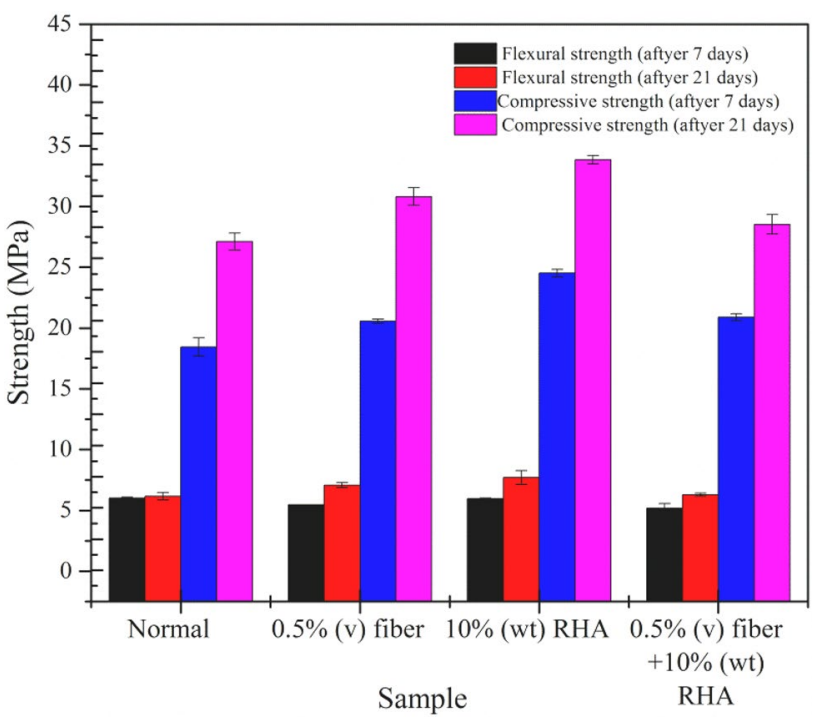

Fig. 9 Flexural and compressive strength of selected mortar after 7 and 21 days

Although nylon fiber reinforcement decreased the flexural strength of mortar after 7 days, it effectively increased the strength after 21 days. This may be because of proper bonding of fibers with mortar after 21 days. This can be justified by the SEM images seen in the Fig. 10, which shows how the addition of RHA has improved bonding between fibers and the cement paste. Addition of RHA also increased the flexural strength, indicating its efficient pozzolanic activity. Mortar with combined nylon fiber and RHA showed a reduction in strength to some extent than mortar with RHA and nylon fiber alone. This may be because of blocking water transfer through the paste.

\subsubsection{Compressive strength}

Figure 9 shows the compressive strength values of the mortar samples after 7 and 21 days. Compressive strength has efficiently increased with the addition of RHA and nylon fibers. Results after 21 days show significant increment in strength, indicating a continued increase of strength at the later ages due to the hydration and $\mathrm{C}-\mathrm{S}-\mathrm{H}$ gel formation of cement and the efficient bonding of fibers to the paste with time $[15,17]$.

\subsubsection{Coefficient of water absorption and the rate of water absorption}

The graphical interpretation for the variation of coefficient of water absorption with type of mortar is given in Fig. 11. This variation indicates a reduction in the sorptivity of mortar with the incorporation of nylon fibers. This may 

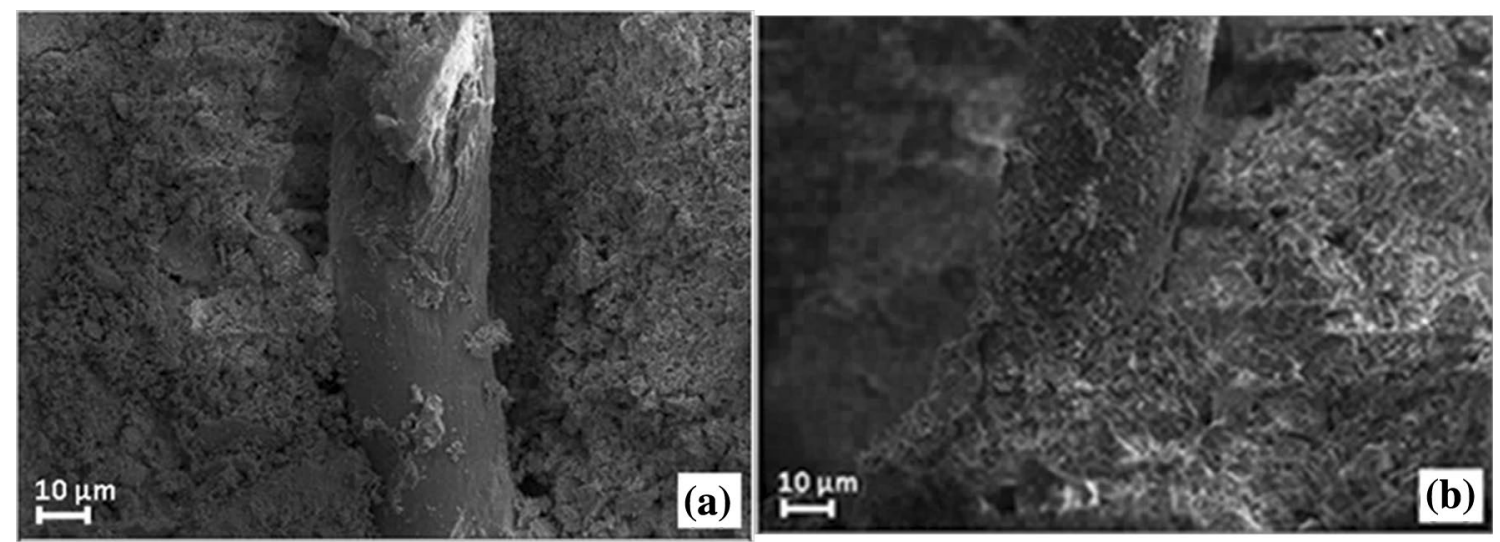

Fig. 10 SEM images showing the bonding of nylon fiber with mortar, a without RHA; b with RHA

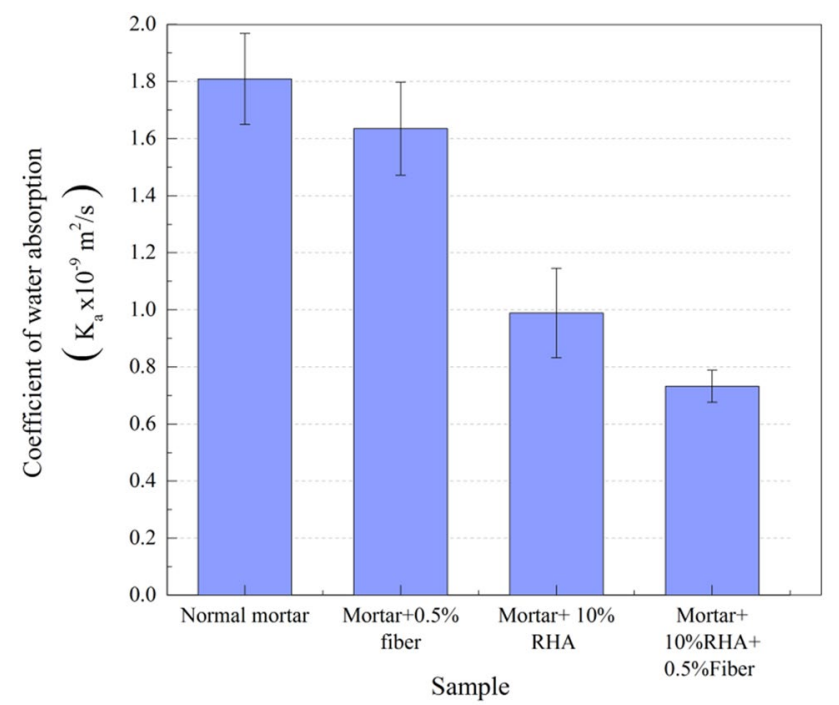

Fig. 11 Variation of coefficient of water absorption with the type of mortar be because the addition of fibers can aid in disrupting or breaking the continuity and interconnectivity of porous channels existing in the composite, thus resulting in lower sorptivity. Also, addition of RHA significantly reduces the water absorption compared with the plain mortar sample, because of the formation of dense $\mathrm{C}-\mathrm{S}-\mathrm{H}$ gel structure reducing the porosity, blocking the capillaries inside the paste $[13,19]$.

The Fig. 12 shows the SEM images of the plain mortar and RHA blended mortar. It clearly shows how the addition of RHA results in a denser structure with less porosity. In the sample incorporated with both RHA and nylon fiber, water absorption coefficient is reduced even more; probably because of RHAs capability of reaching small pores and hence allowing fibers to produce more $\mathrm{C}-\mathrm{S}-\mathrm{H}$ gel, reducing porosity [13].
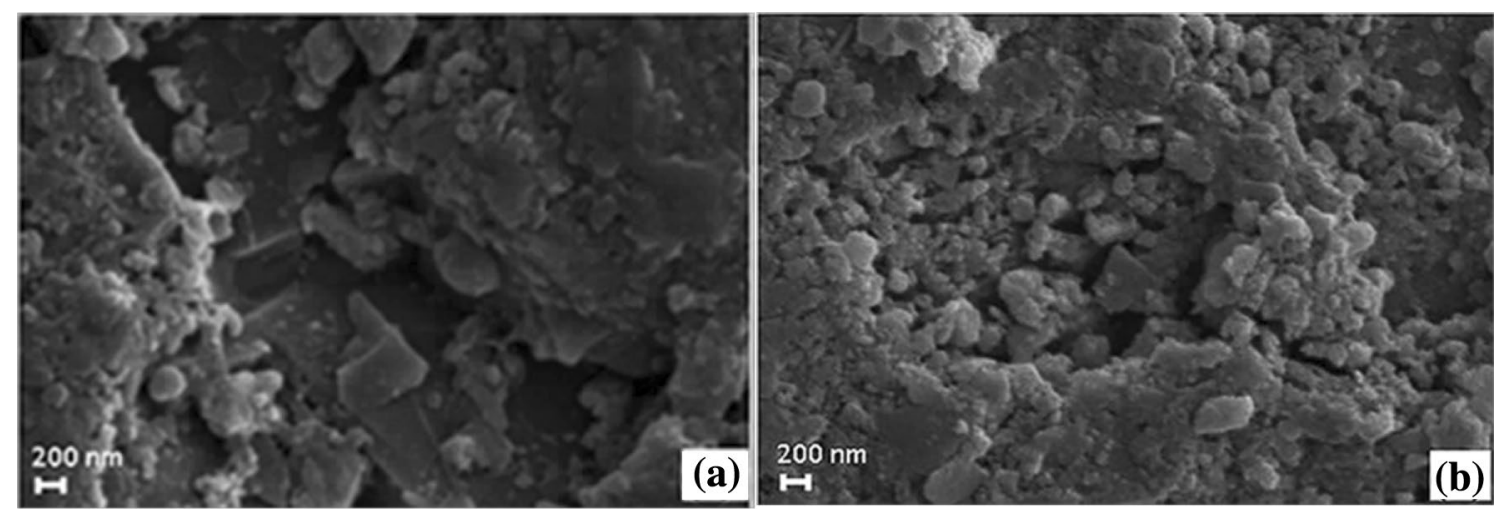

Fig. 12 The SEM images showing the, a plain cement paste and $\mathbf{b}$ cement paste with RHA 
Table 1 Values of the reduced mass for various types of mortar samples

\begin{tabular}{lll}
\hline Sample & \multicolumn{2}{l}{ Reduced mass (g) } \\
\cline { 2 - 3 } & After 10 min & After 20 min \\
\hline Plain mortar & $0.488 \pm 0.045$ & $0.777 \pm 0.067$ \\
Mortar + 0.5 vol\% fiber & $0.300 \pm 0.070$ & $0.481 \pm 0.089$ \\
Mortar + 10 wt\% RHA & $0.469 \pm 0.019$ & $0.744 \pm 0.034$ \\
Mortar +0.5 vol\% & $0.356 \pm 0.075$ & $0.547 \pm 0.103$ \\
fiber + 10 wt\% RHA & & \\
\hline
\end{tabular}

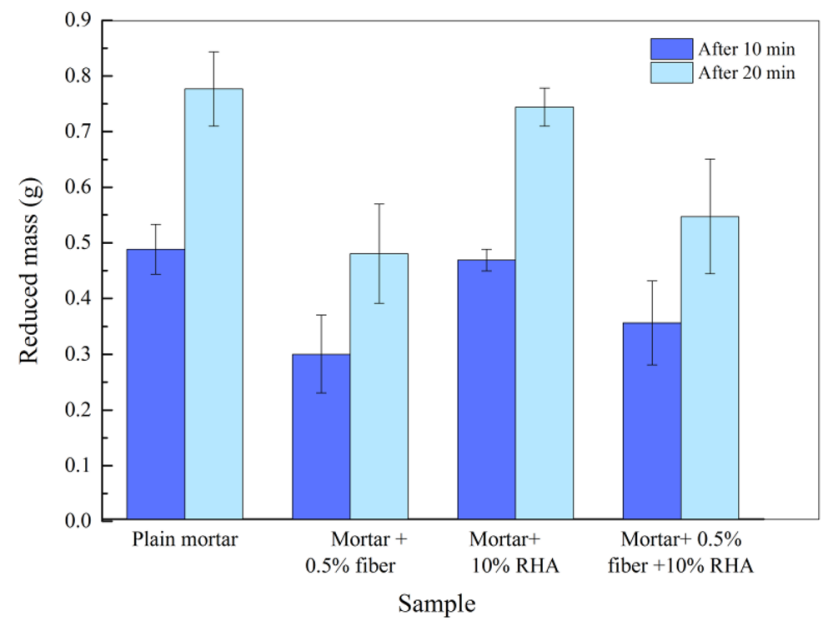

Fig. 13 The graph of reduced mass versus type of mortar

\subsubsection{Abrasion resistance}

Mass reduction gives a clear idea about abrasion resistance where higher mass reduction is an indication of lower resistant of a surface to abrasions. The four types of mortar samples were subjected to brushing over a period of 10 and 20 min respectively, and the mass reduction was obtained. The results obtained are listed below in Table 1 and Fig. 13. Lower reduction of mass after brushing was observed for the nylon fiber reinforced mortar blocks indicating their high abrasion resistance. This may be because nylon fibers can retain during longer time period of stress due to high elasticity. Also, as the frictional coefficient of Nylon is less than that of cement, dragging and abrasions due to the frictional forces may also be less in nylon reinforeced mortar than in plain mortar.

\section{Conclusion}

In this study, the combined effects of nylon fibers and RHA on the mechanical properties and durability of cement mortar were evaluated experimentally. From the results, it can be concluded that, addition of 0.5 vol\% nylon fibers can effectively increase the flexural and compressive strengths of mortar in 21 days as the addition of fibers makes the elements of the composite hold more effectively than plane mortar. But, increasing the amount of fibers more than 0.5 vol\% tends to decrease the strength due to the reduction of the workability of the paste. Also, nylon fibers can increase the abrasion resistance of mortar due to the high elasticity of nylon fibers. Mechanical properties of mortar such as compressive and flexural strength were found to increase with the increase of replacement of cement with RHA up to $10 \mathrm{wt} \%$. The increase in strength is because of the high pozzolanic activity of RHA and the enhancement of the formation of the $\mathrm{C}-\mathrm{S}-\mathrm{H}$ gel. The decrement of strength beyond $10 \%$ of RHA is due to the reduction of formation of $\mathrm{C}-\mathrm{S}-\mathrm{H}$ gel, as increase of $\mathrm{RHA}$ make the paste denser which blocks the water transfer through the paste. Sorptivity of mortar can be decreased efficiently with the replacement of cement with $10 \mathrm{wt} \%$ $\mathrm{RHA}$, and was found to be due to the formation of dense C-S-H structure by RHA. Mortar with combined RHA and nylon fibers showed a significant reduction in sorptivity as the water transfer through paste is blocked by the dense $\mathrm{C}-\mathrm{S}-\mathrm{H}$ gel and nylon fibers blocking the capillaries in the paste. An efficient increment in abrasion resistance was found in mortar with combined RHA and nylon fibers when compared to plain mortar. Hence, it can be concluded that, combined addition of RHA and nylon fibers can increase the performance of conventional mortar efficiently.

Acknowledgements The authors gratefully acknowledge the excellent support given by Prof. B.S.B. Karunarathne, Department of Physics, Faculty of Science, University of Peradeniya, Prof. P.B.R. Dissanayake, Head of the Department/Civil Engineering, Faculty of Engineering, University of Peradeniya and Mr. Y.M. Tikiribanda, Mr. A.G. Jayarathne and all the technical staff of Material laboratory, Department of Civil Engineering, Faculty of Engineering, University of Peradeniya and Mr. K.E.M.C. Abeysinghe and Mr. M.G.S.P Amarasinghe of the Workshop of the Department of Physics, University of Peradeniya. This research did not receive any specific grant from funding agencies in the public, commercial, or not-for-profit sectors.

\section{Compliance with ethical standards}

Conflict of interest The authors declare that they have no competing interests

\section{References}

1. Ganesan K, Rajagopal K, Thangavel K (2007) Evaluation of bagasse ash as supplementary cementitious material. Cement Concrete Compos 29:515-524

2. Giddel MR, Jivan AP (2007) Waste to wealth. Potential of rice husk in India a literature review. In: proceedings of the 
international conference on cleaner technologies and environmental management, Pondicherry, pp 586-590 (proceedings paper-published)

3. Thuadaij N, Nuntiya A (2008) Synthesis and characterization of nano-silica from rice husk ash prepared by precipitation method. Chiang Mai Univ J Nat Sci 7:59-65

4. Bentur A, Mindess S (2007) Fibre reinforced cementitious composites, 2nd edn. Taylor and Francis, New York, pp 2-3

5. Mallick PK (1997) Composites engineering handbook. Marcel Dekker Inc, New York, p 1039

6. ASTM International (1996) ASTM C305-14 standard practice for mechanical mixing of hydraulic cement pastes and mortars of plastic consistency. https://www.astm.org/Standards/C305.htm. Accessed 24 Nov 2016

7. ASTM International (1996) ASTM C348-14 standard test method for flexural strength of hydraulic cement mortars. https://www. astm.org/Standards/C348.htm. Accessed 25 Nov 2016

8. Carlsson LA, Adams DF, Pipes RB (2014) Experimental characterization of advanced composite materials, 4th edn. CRC Press, Boca Raton

9. Mehta PK, Monteiro PJM (2011) Concrete: microstructure, properties, and materials, 3rd edn. McGraw-Hill, New York

10. Galanty PG, Bujtas GA (1992) Modern plastics encyclopedia. McGraw Hill, New York, pp 23-30

11. ASTM International (1996) ASTM C349-14 standard test method for compressive strength of hydraulic cement mortars (using portions of prisms broken in flexure). https://www.astm.org/ Standards/C349.htm. Accessed 25 Nov 2016

12. Powers TC (1968) Properties of fresh concrete. Wiley, New York
13. Ganesan K, Rajagopal K, Thangavel K (2008) Rice husk ash blended cement: assessment of optimal level of replacement for strength and permeability properties of concrete. Constr Build Mater 22:1675-1683

14. ASTM International (1996) ASTM C1403-15 standard test method for rate of water absorption of masonry mortars. http:// www.astm.org/Standards/C1403.htm. Accessed 25 Nov 2016

15. Gambhir ML (2014) Building and construction materials. McGraw Hill Educations (India) Private Limited, New Delhi, pp 205-207

16. Martínez-Barrera G, Menchaca-Campos C, Brostow W, Hernández-López S, Vigueras-Santiago E (2006) Concrete reinforced with irradiated nylon fibers. J Mater Res 21(2):484-491

17. Givi AN, Rashid SA, Aziz FNA, Mohd Salleh MA (2010) Contribution of rice husk ash to the properties of mortar and concrete: a review. J Am Sci 6(3):157-165

18. Bye GC (1999) Portland cement: composition, production and properties, 2nd edn. Thomas Telford Publishing, London

19. Mohseni E, Khotbehsara MM, Naseri F, Monazami M, Sarker $P$ (2016) Polypropylene fiber reinforced cement mortars containing rice husk ash and nano-alumina. Constr Build Mater 111:429-439

Publisher's Note Springer Nature remains neutral with regard to jurisdictional claims in published maps and institutional affiliations. 